\title{
Ventilation improvement in fire smoke control
}

\author{
L. Santarpia, F. Gugliermetti \& G. Zori \\ Department of "Fisica Tecnica", Rome University "La Sapienza", Italy
}

\begin{abstract}
Thermal gradients, wind pressure and mechanical ventilation systems determine a natural airflow travelling the two atmospheres. A fire ignition in a confined space increases thermal gradients and determines a growing smoke flux towards adjacent atmospheres. A free air jet from an air curtain system reduces the exchange airflow and improves fire and smoke compartimentation. Two theoretical analyses are used for the air curtain device dimensioning in emergency conditions. The results provide guidelines to improve the project quality.
\end{abstract}

Keywords: air curtain, confined fire, smoke control, ventilation device.

\section{Introduction}

Smoke management methods can modify smoke movement to protect occupants and fire fighters, and to reduce property damage. Barriers and smoke vents, supplying and exhausting big air quantities (purging dilution) of air in fire space, are traditionally used. Doors coupled with mechanical fans are a very common system in smoke control, while as the single smoke purging is unable to provided the needed air flow attracted through the open door by pressure differences. In many practical applications escape routes towards refuge areas are not equipped with doors, especially in large common-space. In this case the use of air curtains, with the barrier function, could be useful reducing or delaying smoke infiltration towards escape ways. Atria in commercial multi-stories buildings, exhibition halls, sports arenas, railway stations are typical examples of large commonplaces where is suggested to apply an air curtain system.

There are a lot of works and guidelines (NFPA 1995 [1], Klote and Milke 1992 [2], Tamura 1995 [3], Yamana and Tanaka 1985 [4], Hansell and Morgan 1994 [5]), standards and codes devoted to the design of smoke controls, but few papers regards on air curtain system used as a smoke barriers. Preliminary 
studies about air flow rates and pressure field analyses produced by air curtain systems can be find in Gugliermetti and Santarpia $[6,7,8]$

This paper presents a practical application of smoke control by an air curtain systems focused to the emergency ventilation system controlling smoke diffusion in an underground subway station.

\section{Background}

Smoke diffusion in a burning confined space can be analysed in function of the fire dynamic and the exhaust ventilation efficiency [9].

A possible approach for an air curtain device project and to achieve the fire smoke control in a railway deep subway station is to consider a steady fire with an upper layer exhaust $[10,11]$. The stationary fire condition determines a constant smoke production rate. This choice involves a security condition, assuming a constant heat release rate and a well fire oxygenation (maximum heat release rate). In this case the air curtain system can operates protecting emergency exits and reducing evacuation time.

The high temperature fire floats toward the ceiling smoke, making a smoke layer whose thickness is $z_{f}$. The outlet airflow, $G_{\text {out }}$, stabilizes the smoke layer thickness; its value is carried out by a mass balance in the smoke layer control volume (Fig. 1).

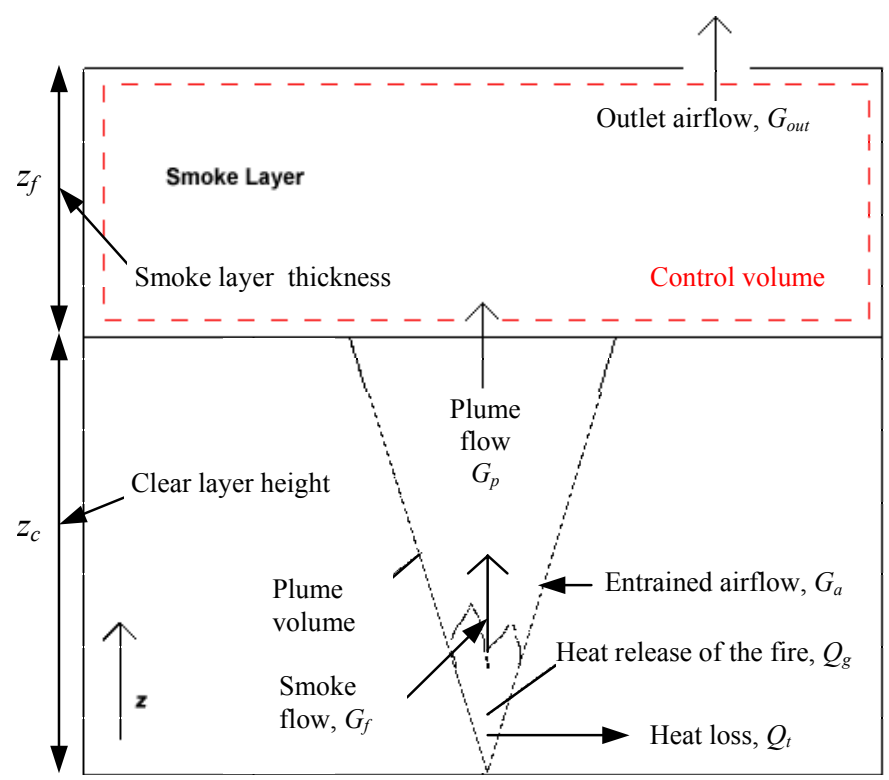

Figure 1: Smoke layer mass balance.

The smoke layer thickness, $z_{f}$, (and consequently the height of lower clear layer, $z_{c}$,) is constant in the time when: $G_{\text {out }}=G_{p}$. The $G_{p}$ flow, coming from the 
plume towards the smoke layer, is a mixture of entrained air, $G_{a}$, and smoke, $G_{f}$. This plume flow generated, $G_{p}$, can be estimated as:

$$
G_{p}=C_{1}\left(Q_{g}-Q_{t}\right)^{\frac{1}{3}}\left(z-z_{0}\right)^{\frac{5}{3}}+C_{2}\left(Q_{g}-Q_{t}\right)
$$

where:

$G_{p} \quad=$ mass flow in plume at height $z, \mathrm{~kg} / \mathrm{s}$;

$Q_{g} \quad=$ heat release rate of fire (HRR), $\mathrm{kW}$;

$Q_{t} \quad=$ fire heat radiative loss (RHRR), $\mathrm{kW}$;

$z \quad=$ height above top of the fuel, $\mathrm{m}$;

$z_{0} \quad=$ plume virtual origin, $\mathrm{m} ;$

$C_{1}=0.071$;

$C_{2}=0.026$.

The amount $\left(Q_{g}-Q_{t}\right)$ symbolizes the convective heat release rate, $Q_{c}$, of the plume (CHRR). The virtual origin, $z_{0}$, is a function of the fire surface and acts shifting the plume origin above the top of the fuel $\left(z_{0}>0\right)$ or below the top of the fuel $\left(z_{0}<0\right)$. The Heskestad's relationship for the virtual origin is:

$$
z_{0}=C_{3} Q_{g}^{\frac{2}{5}}-1.02 D_{f}
$$

where:

$D_{f} \quad=$ diameter of fire, $\mathrm{m}$;

$C_{3}=0.083$.

The effective diameter of a fire, when the surface is rectangular, can be expressed by:

$$
D_{f}=2 \sqrt{\frac{S}{\pi}}
$$

where:

$S \quad=$ surface of fire, $\mathrm{m}^{2}$.

When the fire is starting and developing, before reaching steady conditions (Fig. 1), the low smoke temperature not allows the defined upper and lowers layer creation. In this case the outlet airflow, $G_{\text {out }}$, is calculated supposing a perfect smoke mixing in the confined space where the fire is developed.

The smoke mass balance in the confined volume, $V$, is:

$$
V \cdot d C=G_{f} \cdot d t-G_{\text {out }} \cdot C(t) \cdot d t
$$

where:

$d t \quad=$ infinitesimal time interval, $\mathrm{s}$;

$G_{f} \quad=$ smoke mass production, $\mathrm{kg} / \mathrm{s}$;

$C(t)=$ time dependent smoke mass concentration, $\mathrm{kg}_{\text {smoke }} / \mathrm{kg}_{\text {total }}$; 
Separating the variables:

$$
d t=-\frac{V \cdot d C}{G_{\text {out }} \cdot C(t)-G_{f}}=-\frac{V}{G_{\text {out }}} \cdot \frac{d\left(C(t)-G_{f} / G_{\text {out }}\right)}{\left(C(t)-G_{f} / G_{\text {out }}\right)}
$$

Integrating and setting $C=C_{0}$ when $\mathrm{t}=0$, we can obtain:

$$
C(t)=\frac{\left(G_{\text {out }} \cdot C_{0}-G_{f}\right) \cdot e^{-\frac{G_{\text {out }}}{V} t}+G_{f}}{G_{\text {out }}}
$$

The outlet airflow, $G_{\text {out }}$, can be properly estimated if maximum smoke concentration is lower than security alert level, $C_{s}$, during the evacuation from the subway station.

\section{Ventilation system project}

\subsection{Description}

The depth subway stations are characterized by tunnels (for train transit), central docks and ascending scales. The emergency ventilation system consists in a metallic duct installed at the ceiling connected to the airshaft. The ventilation duct intakes the air and the smoke from several longitudinal grilles disposed with step of $2.5 \mathrm{~m}$.

The surface subway stations are characterized by a rectangular section. In this case the exhaust ventilation system intakes the air and the smoke from two localized airshafts (Fig. 2).

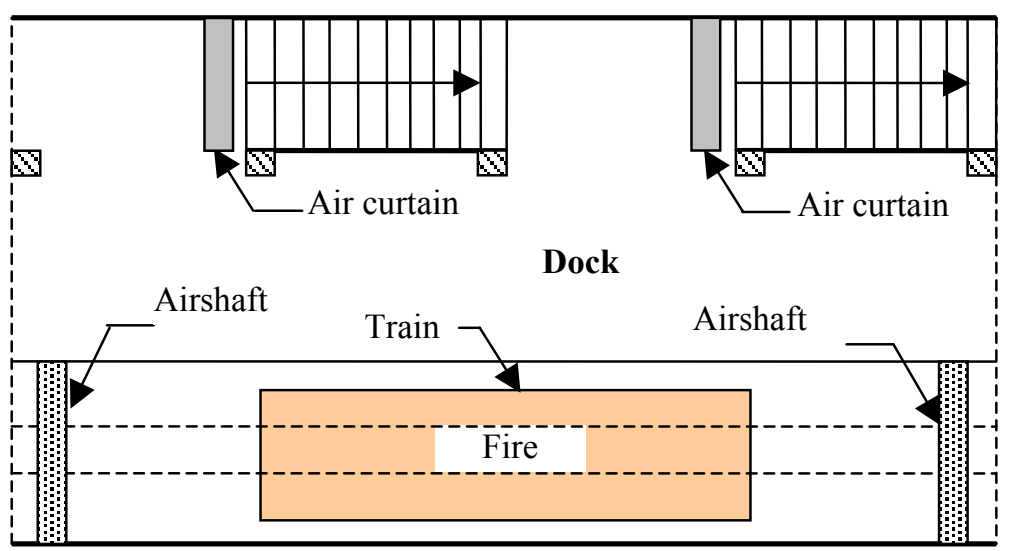

Figure 2: $\quad$ Surface subway station layout.

An air curtain system is installed at the start of each ascending scale (emergency exit). This ventilation device starts to operate when the fire is 
beginning, and the emergency conditions are announced by alert signal, to improve the exit practicability in smoke presence.

Two different operating settings are used to carry out the inlet and outlet ventilation both in normal and emergency conditions.

\subsection{Evacuation time}

Experimental results, published in the scientific literature, [12] shown a temperature value above the fire surface lower than $200{ }^{\circ} \mathrm{C}$. A sprinkler plant (the activation temperature is set to $68^{\circ} \mathrm{C}$ ) assure an effective temperature value lower $200{ }^{\circ} \mathrm{C}$ in the first five minutes (during the evacuation phase). Past 5 minutes, the developing fire becomes uncontrollable and determines not acceptable risks, and the evacuation phase must be completed before this period. The emergency action sequences when a fire starts are shown in Tab. 1.

Table 1: $\quad$ Event-action sequence.

\begin{tabular}{|c|c|c|c|}
\hline Time & Event & Action & Temperature \\
\hline $0 \mathrm{sec}$. & Start fire & Start evacuation & $25^{\circ} \mathrm{C}$ \\
\hline $30 \mathrm{sec}$. & Fire detection & $\begin{array}{c}\text { Start emergency } \\
\text { ventilation system }\end{array}$ & $50^{\circ} \mathrm{C}$ \\
\hline $1 \mathrm{~min}$. & Sprinkler head breaking & $\begin{array}{c}\text { Emergency ventilation } \\
\text { full operative }\end{array}$ & $80^{\circ} \mathrm{C}$ \\
\hline $3 \mathrm{~min}$. & Developing fire & $\begin{array}{c}75 \% \text { of occupants } \\
\text { evacuated }\end{array}$ & $150^{\circ} \mathrm{C}$ \\
\hline $4 \mathrm{~min}$. & Smoke concentration growth & Evacuation complete & $200^{\circ} \mathrm{C}$ \\
\hline
\end{tabular}

\subsection{Project design procedure}

\subsubsection{Outlet ventilation system}

The minimum outlet airflow is determined from the number of the air changes per hour $(\mathrm{ACH})$, parameter fixed by technical provisions, both for normal as for emergency operational conditions (Tab. 2).

Table 2: $\quad$ Air changes per hour $(\mathrm{ACH})$.

\begin{tabular}{|c|c|}
\cline { 2 - 2 } \multicolumn{1}{c|}{} & $\mathrm{ACH}\left(\mathrm{h}^{-1}\right)$ \\
\hline Normal & 2 \\
\hline Emergency & 8 \\
\hline
\end{tabular}

The correct outlet airflow must be determined to avoid danger caused by the high indoor pollution level (smoke, $\mathrm{CO}, \mathrm{CO}_{2}, \ldots$ ) and by the temperature.

3.3.1.1 Developing fire A smoke mass balance in the subway station premise can be used to determine the smoke concentration vs. time during the evacuation phase, $C(t)$. Setting the maximum smoke concentration level, $C_{s}=25 \%$, and the smoke production rate, $G_{f}=16 \mathrm{~kg} / \mathrm{s}$ (that corresponds to $\mathrm{HRR}=3 \mathrm{MW}$ ), the smoke concentration, $C(t)$, is calculated with eqn. (5).

The operating phase, shown in tab. 3 , are considered to compute the smoke concentration. 
Table 3: $\quad$ Operating phase.

\begin{tabular}{|l|c|l|}
\hline \multicolumn{1}{|c|}{ Phase } & Time & \multicolumn{1}{|c|}{ Description } \\
\hline 1 - initial phase & $0<t<1 \mathrm{~min}$. & $\begin{array}{l}\text { time gap between normal and emergency } \\
\text { operating state (normal outlet airflow and } \\
\text { maximum smoke release rate) }\end{array}$ \\
\hline 2 - dilution phase & $1<t<10 \mathrm{~min}$. & $\begin{array}{l}\text { outlet airflow set to emergency state and } \\
\text { maximum smoke release rate. }\end{array}$ \\
\hline 3 - final phase & $\mathrm{t}>10 \mathrm{~min}$. & $\begin{array}{l}\text { outlet airflow set to emergency state and zero } \\
\text { smoke release rate. }\end{array}$ \\
\hline
\end{tabular}

The smoke concentration vs. time are synthesized in tab. 4 and shown in fig. 3.

The emergency outlet airflow, $G_{\text {out }}$, during the fire developing is $155.000 \mathrm{~m}^{3} / \mathrm{h}$ for a depth station and $200.000 \mathrm{~m}^{3} / \mathrm{h}$ for a surface station.

Such disproportion (about 30\% of airflow) is due, for the surface stations, to the directly air extraction from the airshaft, in this case air mixed to smoke outlet airflow is induced from the adjacent tunnel.

Table 4: Concentration vs. time.

\begin{tabular}{|c|c|c|c|c|c|}
\hline \multirow[b]{2}{*}{ Phase } & \multirow[b]{2}{*}{$\begin{array}{l}\text { Time } \\
(\min )\end{array}$} & \multicolumn{2}{|c|}{ Depth station $\left(\mathrm{V}=8000 \mathrm{~m}^{3}\right)$} & \multicolumn{2}{|c|}{ Surface station $\left(V=7000 \mathrm{~m}^{3}\right)$} \\
\hline & & $\begin{array}{c}\text { Ventilation } \\
\left(\mathrm{m}^{3} / \mathrm{h}\right)\end{array}$ & $\begin{array}{c}\text { Smoke } \\
\text { concentration (\%) }\end{array}$ & $\begin{array}{l}\text { Ventilation } \\
\qquad\left(\mathrm{m}^{3} / \mathrm{h}\right)\end{array}$ & $\begin{array}{c}\text { Smoke } \\
\text { concentration (\%) }\end{array}$ \\
\hline \multirow{3}{*}{1} & 0.0 & \multirow{3}{*}{64000} & 0.0 & \multirow{3}{*}{100000} & 0.0 \\
\hline & 0.5 & & 5.8 & & 6.4 \\
\hline & 1.0 & & 11.1 & & 11.9 \\
\hline \multirow{17}{*}{2} & 1.5 & \multirow{17}{*}{155000} & 14.6 & \multirow{17}{*}{200000} & 14.9 \\
\hline & 2.0 & & 17.5 & & 17.2 \\
\hline & 2.5 & & 19.9 & & 18.9 \\
\hline & 3.0 & & 21.8 & & 20.2 \\
\hline & 3.5 & & 23.4 & & 21.1 \\
\hline & 4.0 & & 24.8 & & 21.8 \\
\hline & 4.5 & & 25.8 & & 22.4 \\
\hline & 5.0 & & 26.7 & & 22.8 \\
\hline & 5.5 & & 27.5 & & 23.1 \\
\hline & 6.0 & & 28.1 & & 23.3 \\
\hline & 6.5 & & 28.6 & & 23.5 \\
\hline & 7.0 & & 29.0 & & 23.6 \\
\hline & 7.5 & & 29.4 & & 23.7 \\
\hline & 8.0 & & 29.6 & & 23.8 \\
\hline & 8.5 & & 29.9 & & 23.8 \\
\hline & 9.0 & & 30.1 & & 23.9 \\
\hline & 9.5 & & 30.2 & & 23.9 \\
\hline \multirow{5}{*}{3} & 10.0 & \multirow{5}{*}{155000} & 24.9 & \multirow{5}{*}{200000} & 18.0 \\
\hline & 10.5 & & 20.5 & & 13.5 \\
\hline & 11.0 & & 16.9 & & 10.1 \\
\hline & 11.5 & & 13.9 & & 7.6 \\
\hline & 12.0 & & 11.5 & & 5.7 \\
\hline
\end{tabular}

3.3.1.2 Steady fire When steady conditions are reached the dimensioning the extraction system can be carried out by the model of the plume illustrated $(\S 2)$. The dimensioning is obtained directly through the esteem of the HRR and it 
leads to the same result obtained following the methodology illustrated in $\S 3.3 .1 .1$.

Assuming the following values for the calculations:

- $\quad \mathrm{HRR}=3 \mathrm{MW}$

- Convective heat fraction $\left(Q_{c} / Q_{t}\right)=0,7$

- $\quad$ Fire surface $=30 \mathrm{~m}^{2}$

A value for virtual origin, $z_{0}=-4,26 \mathrm{~m}$, and an outlet airflow $G_{\text {out }}=40 \mathrm{~m}^{3} / \mathrm{s}$ $\left(144000 \mathrm{~m}^{3} / \mathrm{h}\right)$, are obtained. Such values are sufficient to determine a free height from smoke, zc, constant in the time, of approximately $5 \mathrm{~m}$ above the dock.

Therefore the outlet airflow $\left(155000 \mathrm{~m}^{3} / \mathrm{h}\right)$ is consistent in order to guarantee the ventilation emergency to complete the evacuation of the premises (about 5 min.). For the surface stations the outlet grille airflow must be $30 \%$ greater to compensate the air-smoke entrained from the tunnels.

The air changes per hour carried out with the present model are 19, approximately $60 \%$ greater than the provision values suggested as minimum value (Tab. 2).

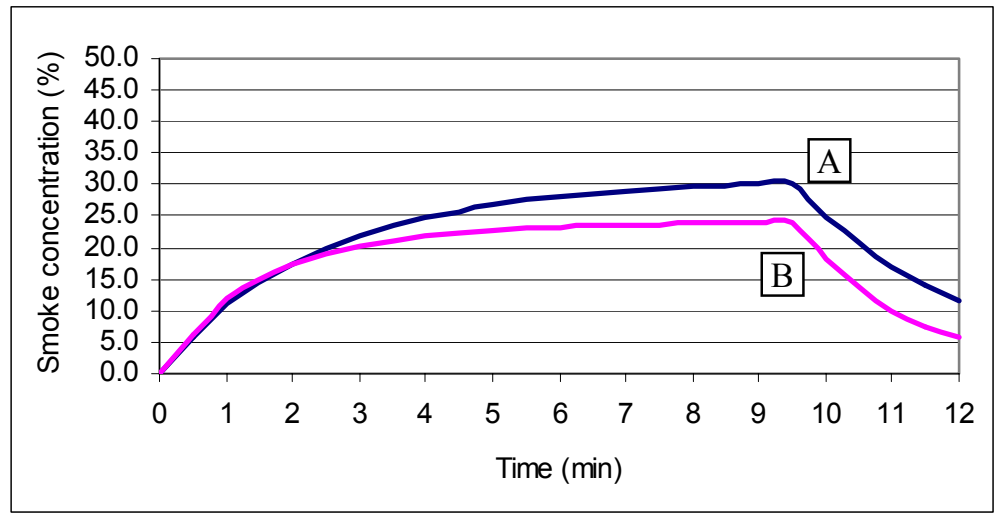

Figure 3: Depth (A) and Surface (B) stations smoke concentration vs. time.

\subsubsection{Inlet airflow}

The outlet airflow going out to the premises captures external renewal air through the galleries and the exodus way. This airflow, flowing in opposite exodus versus, contrasts the premise evacuation (the difference of pressure in correspondence of the emergency exits could interfere with the opening of the fire doors). A solution at this problem is the inlet airflow system.

To avoid the smoke diffusion in exodus way a localized inlet grille is installed on the exit proximity. The vertical inlet airflow width creates a pressure gradient contrasting the air jet flowing on the communicating doorway. The air jet can be considered as a linear vertical air curtain system operating with not recirculated airflow [13]. 
The project design can be guided by ASHRAE procedure, therefore, in emergency operating conditions, it can be useful applied the procedure presented in Tab. 5 by Santarpia et al. [14]. The procedure is based on a momentum ratio, $r_{M}=M / M_{0}$, where $M$ is the airflow momentum on the exodus way when the air curtain is OFF and $\mathrm{M}_{0}$ is the air curtain jet momentum.

Table 5: $\quad$ Design procedure.

\begin{tabular}{|c|c|c|c|}
\hline Setting: & Width of push grille & $m$ & $d$ \\
\hline & Door height & $\mathrm{m}$ & $H_{d}$ \\
\hline & Outdoor temperature & ${ }^{\circ} \mathrm{C}$ & $t_{e}$ \\
\hline & Indoor temperature & ${ }^{\circ} \mathrm{C}$ & $t_{a}$ \\
\hline & Velocity coefficient & - & $\phi=0.7$ \\
\hline & Width of opening & $\mathrm{m}$ & $\mathrm{L}$ \\
\hline & Momentum ratio & - & $r_{M}=\frac{M}{M_{0}}$ \\
\hline \multirow[t]{3}{*}{$\begin{array}{l}\text { Carrying } \\
\text { out: }\end{array}$} & $\begin{array}{l}\text { Pressure gradient } \\
\left(\rho_{e} \text { outdoor air density }\right. \\
\left.\rho_{a} \text { indoor air density }\right) \\
\end{array}$ & $\mathrm{Pa}$ & $\Delta p_{\max }=\left(\rho_{e}-\rho_{a}\right) \cdot g \cdot \frac{H_{d}}{2}$ \\
\hline & $\begin{array}{l}\text { The average speed of the } \\
\text { air flow through the } \\
\text { opening when the air } \\
\text { curtain is OFF }\end{array}$ & $\mathrm{m} / \mathrm{s}$ & $v_{m}=\frac{2}{3} \phi \cdot \sqrt{\frac{2 \cdot \Delta p_{\max }}{\rho_{m}}}$ \\
\hline & $\begin{array}{l}\text { Air curtain vertical } \\
\text { discharge velocity }\end{array}$ & $\mathrm{m} / \mathrm{s}$ & $v_{i n}=\sqrt{\frac{r_{M} v_{m}^{2} \cdot \frac{H_{d}}{2} \cdot \rho_{m}}{d \cdot \rho_{i n}}}$ \\
\hline & Air curtain airflow & $\mathrm{m}^{3} / \mathrm{h}$ & $G_{i n, t o t}=3600 \cdot d \cdot L \cdot v_{i n}$ \\
\hline
\end{tabular}

The principal technical dimensioning parameter is the momentum ratio; in normal operating condition $r_{M}$ can be set to 10 , while in emergency operating condition $r_{M}$ can be set to 32 .

In Tab. 6 are shown the dimensioning data carried out both with ASHRAE method and with the Tab. 5 procedure.

On the Authors procedure (tab. 5), the air curtain airflow, $G_{i n, t o t}$, can be carried out in function of the indoor steady temperature $T_{a}$, door height $H_{d}$, and air curtain grille $d$, with:

$$
G_{i n, t o t}=G_{i n} \cdot L=3600 \cdot H_{d} \cdot \sqrt{r_{M}} \cdot \sqrt{\frac{2}{9} g \phi^{2}} \cdot \sqrt{d} \cdot \sqrt{\frac{\theta_{a}}{\theta_{e}}-1} \cdot L
$$

$g$ is the gravity acceleration, $\theta_{a}$ and $\theta_{e}$ are the indoor and outdoor Kelvin temperature. 


\section{Remarks}

The Authors air curtain airflow dimensioning procedure is more precautionary than ASHRAE method in emergency condition (airflow 20-30\% greater).

Moreover the inlet airflow balances the outlet airflow and improves security in exodus ways.

Table 6: Design results.

\begin{tabular}{|c|c|c|c|c|c|}
\hline & \multicolumn{2}{|c|}{ ASHRAE } & \multicolumn{2}{|c|}{ Authors model } & \multirow[b]{2}{*}{ Unit } \\
\hline Setting: & Depth & Surface & Depth & Surface & \\
\hline $\mathrm{E}=$ & 0.3 & 0.3 & - & - & \\
\hline $\mathrm{f}=$ & 10 & 10 & - & - & \\
\hline $\mathrm{d}=$ & - & - & 0.6 & 0.6 & $\mathrm{~m}$ \\
\hline$r_{M}=$ & - & - & 32 & 32 & \\
\hline $\mathrm{H}=$ & 3.2 & 2.7 & 3.2 & 2.7 & $\mathrm{~m}$ \\
\hline $\mathrm{Te}=$ & 25 & 25 & 25 & 25 & ${ }^{\circ} \mathrm{C}$ \\
\hline $\mathrm{Ta}=$ & 200 & 200 & 200 & 200 & ${ }^{\circ} \mathrm{C}$ \\
\hline $\mathrm{Tem}=$ & 200 & 200 & 200 & 200 & ${ }^{\circ} \mathrm{C}$ \\
\hline \multicolumn{6}{|l|}{ Carrying out: } \\
\hline$d=\frac{H_{d}}{f}=$ & 0.32 & 0.27 & - & - & $\mathrm{m}$ \\
\hline$\rho_{e}=$ & 1.18 & 1.18 & 1.18 & 1.18 & $\mathrm{~kg} / \mathrm{m}^{3}$ \\
\hline$\rho_{a}=\rho_{i n}=$ & 0.75 & 0.75 & 0.75 & 0.75 & $\mathrm{~kg} / \mathrm{m}^{3}$ \\
\hline$\rho_{m}=$ & 0.968 & 0.968 & 0.968 & 0.968 & $\mathrm{~kg} / \mathrm{m}^{3}$ \\
\hline$\Delta p_{\max }=$ & 6.74 & 5.7 & 6.74 & 5.7 & $\mathrm{~Pa}$ \\
\hline$v_{i n}=\sqrt{\frac{2 \cdot \Delta p \cdot f}{\beta_{0} \cdot \rho_{\text {in }} \cdot E}}$ & 23.4 & 21.5 & - & - & $\mathrm{m} / \mathrm{s}$ \\
\hline$v_{m}=\frac{2}{3} v_{\max }=$ & - & - & 1.74 & 1.60 & $\mathrm{~m} / \mathrm{s}$ \\
\hline$v_{i n}=\sqrt{\frac{r_{M} v_{m}^{2} \cdot \frac{H_{d}}{2} \cdot \rho_{m}}{d \cdot \rho_{i n}}}$ & - & - & 22.4 & 18.9 & $\mathrm{~m} / \mathrm{s}$ \\
\hline$G_{i n}=3600 \cdot v_{i n} \cdot d=$ & 26944 & 20883 & 32256 & 27216 & $\mathrm{~m}^{3} / \mathrm{h} \times \mathrm{m}$ \\
\hline $\mathrm{L}=$ & 4 & 7,2 & 4 & 7,2 & $\mathrm{~m}$ \\
\hline$G_{i n, t o t} \approx$ & 108000 & 150000 & 129000 & 196000 & $\mathrm{~m}^{3} / \mathrm{h}$ \\
\hline$G_{\text {out }} \approx$ & 155000 & 20000 & 155000 & 20000 & $\mathrm{~m}^{3} / \mathrm{h}$ \\
\hline$\Delta \mathrm{G}=G_{\text {out }}-G_{\text {in, tot }}=$ & 47000 & 50000 & 26000 & 4000 & $\mathrm{~m}^{3} / \mathrm{h}$ \\
\hline
\end{tabular}




\section{Acknowledgement}

This work has been supported with the economical contribute of the "Fondazione Cassa di Risparmio di Roma" in the frame of a national program devoted to the human health protection.

\section{References}

[1] NFPA, 1995. NFPA 92 B. Guide for smoke management systems in malls, atria and large areas. Quincy, Mass: National Fire Protection Association

[2] Klote J.H. and J.A. Milke, 1992. Design of smoke management systems. Atlanta, ASHRAE: American Society of heating, Refrigerating and AirConditioning Engineers Inc.

[3] Tamura G.T., 1995. Smoke movement and control in high-rise buildings. Quincy, Mass, NFPA: National Fire Protection Association.

[4] Yamana T. and T. Tanaka, 1985. Smoke control in large spaces. Fire science 5: 41-54

[5] Hansell G.O. and H.P. Morgan, 1994. Design approaches for smoke control in atrium buildings. BR-258. Garston, U.K., BRE: Building Research Establishment.

[6] Santarpia L., Gugliermetti F., 2002. Smoke movement and management in larges spaces. Heat and Technology (Vol.1). - International Journal of heat and technology.

[7] Santarpia L, Gugliermetti F., 2000. Air curtains to reduce outdoor pollutants infiltration through buildings aperture. Proc of Intren Conf. HB2000, Helsinki, August 5-10.

[8] Santarpia L. Gugliermetti F., 1999. A phenomenological approach to the performance of shutter type air curtains Proc. Of Air pollution 99, 27-29 July, San Francisco.

[9] Klote J.H., 1994. Method of predicting smoke movement in atria with application to smoke management. NIST- 5516. Gaithersburg, NIST: National Institute of Standards and Technology.

[10] Klote J.H., 1997/1. Prediction of smoke movement in Atria: Part IPhysical concepts. Ashrae Transactions: 103(2).

[11] Klote J.H., 1997/2. Prediction of smoke movement in Atria: Part IIApplication to smoke management. Ashrae Transactions: 103(2).

[12] Heskestad G., 1988. Fire Plumes- Handbook of fire protection engineering. Boston, Mass, SFPE: Society of Fire Protection Engineers

[13] ASHRAE HVAC Application Handbook, 1999. Handbook Editor, ASHRAE, 1791. Tullie Circle, Atlanta.

[14] Santarpia L., Gugliermetti F., Zori G. Dynamic efficiency of air curtain systems. HEFAT2005, 4th International Conference on Heat Transfer, Fluid Mechanics and Thermodynamics. 19-23 September 2005, Cairo, Egypt. 